6-1-1998

\title{
An Empirical Test of a Communibiological Model of Trait Verbal Aggressiveness
}

\author{
Kristin M. Valencic \\ Michael J. Beatty \\ Jill E. Rudd \\ Cleveland State University, J.RUDD@csuohio.edu \\ Jean A. Dobos \\ Alan D. Heisel
}

Follow this and additional works at: https://engagedscholarship.csuohio.edu/clcom_facpub

Part of the Psychology Commons, and the Speech and Rhetorical Studies Commons

How does access to this work benefit you? Let us know!

\section{Publisher's Statement}

This is an Accepted Manuscript of an article published by Taylor \& Francis in Communication Quarterly on 01/06/1998, available online: http://www.tandfonline.com/10.1080/ 01463379809370105

\section{Recommended Citation}

Valencic, Kristin M.; Beatty, Michael J.; Rudd, Jill E.; Dobos, Jean A.; and Heisel, Alan D., "An Empirical Test of a Communibiological Model of Trait Verbal Aggressiveness" (1998). Communication Faculty Publications. 58.

https://engagedscholarship.csuohio.edu/clcom_facpub/58

This Article is brought to you for free and open access by the School of Communication at EngagedScholarship@CSU. It has been accepted for inclusion in Communication Faculty Publications by an authorized administrator of EngagedScholarship@CSU. For more information, please contact library.es@csuohio.edu. 


\section{An Empirical Test of A Communibiological Model of Trait Verbal Aggressiveness}

Kristin Marie Valencic, Michael J. Beatty, Jill E. Rudd, Jean A. Dobos, and Alan D. Heisel 
ver a decade ago, Infante and Wigley (1986) proposed a conceptualization of trait verbal aggressiveness, emphasizing individual differences in the predisposition to attack "the self-concept of another person instead of, or in addition to, the person's position on a topic of communication" (p. 61). The contribution of Infante and Wigley's theoretical work has been underscored by the findings of numerous investigations into the nature, correlates, and consequences of trait verbal aggressiveness in a variety of social contexts (For comprehensive reviews, see Infante, 1987; Infante \& Rancer, 1996; Wigley, 1998).

Until recently, however, the underlying mechanisms that contribute to individual differences in trait verbal aggressiveness have gone comparatively understudied. Drawing from principles established in the psychobiological research literature (e.g., Eysenck, 1991; Eysenck \& Eysenck, 1985; Gray, 1991; Steinmetz, 1994; Strelau, 1994; Zajonc \& McIntosh, 1992; Zuckerman, 1995), Beatty and McCroskey (1997) reasoned that individual differences in the reactivity of neurobiological systems account for individual differences in trait verbal aggressiveness. These authors, however, note that while consistent with extant psychobiological research, the product of their theorizing should be viewed as a "working" model that requires testing, refinement, and perhaps further elaboration. The present study was undertaken to empirically test hypotheses derived from Beatty and McCroskey's (1997) model of trait verbal aggressiveness.

\section{Conceptual Perspective}

\section{THEORETIC RATIONALE}

Beatty and McCroskey (1998) coined the term communibiology to refer to the conceptualization of communicative activity as products of individual differences in neurobiological functioning. ${ }^{1}$ Most of the psychobiological work which informs the communibiological paradigm has been conducted under the rubric of temperament, which may be defined as biologically rooted individual differences in behavioral tendencies that are present early in life and are relatively stable across all kinds of situations and over the course of time (Bates, 1989, p. 4). Many of the behaviors studied in the temperament literature are immediately recognizable as significant interpersonal functions such as empathy, assertiveness, and nurturance, leading Bates (1989) to remark that "temperament is manifest largely in the context of social interaction" (p. 4).

In recent years, biologically-oriented scholars have made profound advances in the understanding of social behavior which are supported by three research paradigms. First, evidence of the heritability of many social traits has been gleaned from studies of identical and fraternal twins who were raised apart and those who were raised together. Most relevant to the development of the communibiological model of trait verbal aggressiveness are the twins studies which document a substantial genetic component to aggressive antisocial behavior (e.g., Cates, Houston, Vavak, Crawfor, \& Uttley, 1993; Coccaro, Bergeman, \& McClearn, 1993; Edelbrock, Rende, Plomin, \& Thompson, 1995; Eley, 1997; Rushton et al., 1986). The genetic contribution to these traits is underscored by (1) the observation of larger correlations for identical than fraternal twins, and (2) the similarity of correlations for identical twins who were raised apart and those who were raised together (Zuckerman, 1994).

Second, research focused on the biochemical signatures of specific neuroanatomical activity has advanced our understanding of the neurobiological processes which 
produce temperamental displays (For a general review and discussion, Zuckerman, 1995). In particular, considerable research effort has been devoted to the biochemistry of aggressiveness and the mapping of the neurobiological circuitry associated with aggressive antisocial behavior (e.g., Bernhardt, 1997; Gray, 1991; Marieb \& Mallatt, 1992; Panksepp, 1982, 1986; Spoont, 1992, 1996; Steinmetz, 1994; Strelau, 1994; Weiger \& Bear, 1988; Zuckerman, 1995). Within this line of inquiry, scholars have induced lower levels of aggressiveness through the administration of drugs designed to counteract suspected neurobiological abnormalities (e.g., Kaplan, Sadock, \& Greb, 1994; Kavoussi, Liu, \& Coccaro, 1994; Mattes, 1990).

Third, propositions in the temperament literature are further supported by numerous observational studies which document behavioral markers of neurobiological processes during infancy (e.g., Bates, 1987; Calkins \& Fox, 1992; Nelson, 1994; Steinmetz, 1994; Thomas \& Chess, 1977). Behavioral evidence of both nonaffective forms of aggression and rage are detectable within hours of birth (e.g., Parens, 1989).

\section{Neurobiological Model of Trait Verbal Aggressiveness}

The trait verbal aggressiveness literature provides ample documentation of relatively stable individual differences in predispositions to employ aggressive forms of communication, especially when opposition to communicative goals is encountered (See Infante \& Rancer, 1996; Wigley, 1998). Extending the principles founded in the temperament literature cited earlier, Beatty and McCroskey (1997) posited a model depicting (1) the neurobiological underpinnings of individual differences in the inclination to deploy aggressive messages, and (2) the neurobiological processes that moderate neurobiological impulses to aggress. These authors based much of their theorizing on the neurobiological work of Gray (1991). Gray's model is especially useful in the study of trait verbal aggressiveness because (1) it integrates the neurobiological structures into three interconnected behavior systems (i.e., the fight or flight system - FFS, the behavioral inhibition system - BIS, and the behavioral approach system - BAS), all of which are potentially involved in the instigation and inhibition of aggressive acts, and (2) individual differences in thresholds for triggering each system are described. Relating individual differences in the neurobiological systems to temperament, Gray (1991) pointed out that "temperament reflects parameter values ... that determine for any individual, the operating characteristics of our three emotional systems" (p. 23). Moreover, "the major dimensions of personality . . . are created by individual differences in such parameter values" (Gray, 1991, p. 23).

Neurobiological bases of aggressive impulses. Of the three neurobiological systems in Gray's (1991) model, the fight or flight system (FFS) is most strongly related to the impulse to aggress. This system interconnects the basolateral and centromedial nuclei of the amygdala, the ventromedial nucleus of the hypothalamus, the central gray area of the midbrain, and the somatic and motor nuclei of the lower brain stem (Gray, 1991). These anatomical components are mostly located on the underside of the brain (For an elementary description see Marieb \& Mallatt, 1992). According to Gray (1991), detection of painful or frustrating input stimulates amygdaloid, hypothalamic, and midbrain functioning, which combine to coordinate the brain stem effectors in producing defensive or aggressive behavior. The conceptual significance of frustration as input to the FFS resides in the importance that Infante (1987) placed on frustration as a stimulant of verbal aggressiveness.

Considerable published research conducted by scholars other than Gray supports 
the central roles of the hypothalamus (Adams \& Victor, 1993; Bernhardt, 1997; Marieb \& Mallatt, 1992; Panksepp, 1982, 1986), the amygdala (Bernhardt, 1997; Spoont, 1996) and the midbrain (Spoont, 1992) in aggressive behavior. For example, both lesions of the ventromedial hypothalamus (Panksepp, 1982) and opiate projections from the amygdala to it (Panksepp, 1986) inhibit aggressiveness and stimulate prosocial behavior such as friendliness, bonding, and comforting behavior. Gray (1991) contended that individual differences in FFS reactivity account for differences in aggressiveness as well as other temperament traits such as psychoticism (Eysenck \& Eysenck, 1985). Following Gray's lead, Beatty and McCroskey (1997) propose that individual differences in FFS reactivity account for the impulse to respond aggressively to frustration experienced during interaction. According to Gray (1991), however, aggressive impulses resulting from FFS stimulation are not sufficient to produce particular actions. Rather, the ways in which FFS activity finds expression are moderated by a second neurobiological system, the behavioral inhibition system (BIS).

Neurobiological bases of inhibition. Gray (1991) describes the BIS as a set of holistically functioning neurobiological circuits linking the hippocampus, the subiculum, and the septum with the limbic system. Novel stimuli and input implicating potential punishment or cessation of reward activate the BIS. When activated, the BIS produces increased arousal due to its connection with the limbic system, increased attentional focus on threatening stimuli and behavior is halted. Anxiety prone individuals typically possess low thresholds for BIS activation (For an extensive review of research connecting the BIS reactivity to anxiety, see Beatty, McCroskey, \& Heisel, 1998).

In general, anxiety produced by BIS activation inhibits behavioral expressions of aggressive impulses (Gray, 1991). Several personality theorists point out that without BIS interference, FFS stimulation expresses itself in the form of extremely assaultive responses (Gray, 1991; Lykken, 1995; Zuckerman, 1995). Analyses of blood samples, for example, reveal biochemical patterns indicative of weak BIS potential for both psychopaths (Arnett, Howland, Smith, \& Newmann, 1993) and compulsive repeat offenders (Zuckerman, 1995). Also consistent with the inhibitory effects of BIS activity, some studies indicate that the administration of anti-anxiety drugs results in increased aggressiveness in patients diagnosed with borderline personality disorders (e.g., Cowdry \& Gardner, 1988; Soloff, George, Nathan, Schulz, \& Peril, 1986).

Because verbal aggressiveness represents a weaker expression of FFS activation compared to physical violence, Beatty and McCroskey (1997) speculated that some predisposition toward BIS interference among persons high in trait verbal aggressiveness was required to prevent immediate, physical attack in response to FFS arousal. There exists empirical evidence that is consistent with this conjecture. Indeed, although scholars have noted that (1) verbal hostility can escalate into violence (e.g., deTurck, 1987; Infante, 1987; Infante \& Rancer, 1996; Roloff, 1996) and (2) predispositions toward verbal hostility and physical aggression are moderately correlated (e.g., Lish, Kavoussi, \& Caccaro, 1996), research also indicates that extremely assaultive persons actually score lower on a measure of verbal aggressiveness than do moderately assaultive and nonviolent persons (see Geen, 1990), indicating some degree of inhibition for those inclined toward verbal aggression. Consistent with the inhibition notion, Infante and Wigley (1986) reported a positive, albeit small, correlation between communication apprehension and trait verbal aggressiveness scores. Following the lead of personality theorists, Beatty and 
McCroskey (1997) proposed that individual levels of trait verbal aggressiveness depended on the relative strength or thresholds for BIS and FFS activation.

Neurobiological bases for proactive verbal aggressiveness. A conceptual distinction between reactive (or affective) and proactive (or instrumental) aggressiveness has been acknowledged in the aggression literature (Dodge \& Coie, 1987). Reactive aggression consists of hostile, defensive counterattacks to the actions of others. The proposed formulation involving the relative reactivity of FFS and BIS addresses the neurobiology of reactive aggressiveness. Proactive aggressiveness, on the other hand, consists of unprovoked hostile action which is initiated for the purpose of facilitating goal achievement through interpersonal dominance. Beatty and McCroskey (1997) posit Gray's (1991) behavioral approach system (BAS), which is activated by potential rewards and energizes goal directed behavior into irritable aggression when efforts are blocked, as a moderator of FFS activity in the formation of proactive aggressiveness.

Anatomically, the BAS consists of the basal nuclei, the neocortical regions that connect to it, the dopaminergic fibers that originate in the midbrain, and the thalamic nuclei (Gray, 1991). As with the FFS and BIS, reactivity in the BAS varies across individuals and these individual differences are instrumental in defining personality types. For example, low thresholds for BAS activation are common to extraverts (Gray, 1991). Although Infante and Wigley's (1986) measure of verbal aggressiveness is dominated by reactive-type items (respondents are requested to indicate frequency of verbal aggression in reaction to the other's behavior), studies show an overlap in the inclinations to act in reactive and proactive ways (Dodge \& Coie, 1987). If trait verbal aggressiveness as conceptualized and measured on the VAS includes predispositions toward proactive aggressiveness, BAS reactivity would be expected in the neurobiological profile of persons high in the trait.

\section{Development of Hypotheses}

Personality measures as indicators of neurobiological reactivity. As mentioned, Gray (1991) noted that individual differences in the reactivity of the FFS, BIS, and BAS underlie "the major dimensions of personality" (p. 23). Gray's reference was made in the context of recent factor analytic work by personality theorists, supported by biological studies, which has reduced the basic dimensions of personality to between three and five (Zuckerman, 1995). In particular, Gray (1991) maintained that FFS, BIS, and BAS reactivity were represented by Eysenck's (Eysenck \& Eysenck, 1985) psychoticism, neuroticism, and extraversion personality dimensions, which are known as the "Big Three" in personality theory (Zuckerman, 1995).

According to Eysenck, extraversion refers to an outward orientation toward life, focused on activities outside oneself, whereas introversion refers to a tendency toward internal functions such as introspection. Neuroticism refers to emotional instability, most often manifest as general anxiousness. Eysenck used the term psychoticism to refer to a lack of self-control, most frequently manifest in anger outbursts.

The proposition that psychoticism, neuroticism, and extraversion represent psychological manifestations of Gray's three neurobiological systems is supported by an impressive body of research consisting of (1) studies of identical twins showing that these three personality dimensions are among the more heritable traits (see Eysenck, 1986; Eysenck \& Eysenck, 1985; Eysenck, 1991), and (2) numerous biologicallyoriented studies demonstrating that individual differences in the neurobiological 
functioning are consistent with the neurobiological circuitry proposed by Gray (For extensive reviews, see Eysenck, 1991; Eysenck \& Eysenck, 1985; Fowles, 1980; Gray, 1991; Nelson, 1994; Rothbart, Derryberry, \& Posner, 1994; Steinmetz, 1994; Stelmack, 1990; Strelau, 1983; Zuckerman, 1995).

Eysenck (1986, p. 14) integrated and summarized the interpersonal relevance of the research suggesting that psychoticism $(P)$, extraversion $(E)$, and neuroticism $(N)$ "embody the three ways in which individuals can interact: hostility and aggression (P), cooperativeness and sociability (E), and fearful avoidance (N)." Furthermore, Eysenck and Eysenck (1985) reviewed research which indicated that secondary traits (e.g., shyness) represent blends of $E, N$, and $P$. Working from this perspective, Beatty, McCroskey, and Heisel (1998) employed measures of neuroticism and extraversion as psychological manifestations of BIS and BAS reactivity to predict communication apprehension scores. A similar strategy was followed in the present study.

Research hypotheses. Based on the reasoning that FFS reactivity underlies trait verbal aggressiveness and that psychoticism represents a psychological manifestation of individual differences in FFS reactivity, the following hypothesis was advanced:

H1: There will be a positive and significant correlation between trait verbal aggressiveness scores and psychoticism scores.

Because, according to Beatty and McCroskey (1997) BIS reactivity moderates the effects of FFS activity on behavior, the following hypothesis was posited:

H2: The interaction of neuroticism and psychoticism will account for a significant portion of the variance in trait verbal aggressiveness scores.

Furthermore, Beatty and McCroskey (1997) argued that, to the extent trait verbal aggressiveness contains a proactive function, BAS reactivity should be positively associated with trait verbal aggressiveness for individuals high in FFS reactivity. Therefore, the following hypothesis was tested:

H3: The interaction of extraversion and psychoticism should account for a significant portion of variance in trait aggressiveness scores.

\section{General Procedure}

\section{METHOD}

Two hundred and ninety three undergraduates (males $n=115$; females $n=178$ ) enrolled in introductory communication courses at a mideastern university participated in the present study. Each participant responded to a set of materials consisting of Infante and Wigley's (1986) verbal aggressiveness scale (VAS), measures of extraversion, neuroticism, and psychoticism developed by Eysenck and his colleagues (Eysenck \& Eysenck, 1985; Eysenck, Eysenck, \& Barrett, 1985) and several distractor items. Participants were debriefed about the purpose of the study after the data were collected. 


\section{Measurement}

Extraversion, neuroticism, and psychoticism. The 10-item measures of extraversion $(M=37.89, s d=6.03$, alpha $=.82)$ and neuroticism $(M=27.52, s d=7.26$, alpha $=.81)$ developed and validated by Eysenck and his colleagues (Eysenck \& Eysenck, 1985) were employed in the present study. Psychoticism $(M=25.95, s d=6.79$, alpha $=.76)$ was measured using the revised 12-item instrument developed and validated by Eysenck, Eysenck, and Barrett, (1985). All three instruments featured a Likert-type response format identical to that used in the VAS. The small correlations among these three measures observed in the present study were consistent with Eysenck's (Eysenck \& Eysenck, 1985) claim that $E, N$, and $P$ are relatively uncorrelated $(E \times N=-.11$, n.s.; $P$ $\times \mathrm{N}=.09$, n.s.; $\mathrm{E} \times \mathrm{P}=-.17, p<.05) .^{2}$

Trait verbal aggressiveness. The predisposition to deploy aggressive messages was measured using Infante and Wigley's (1986) twenty item Verbal Aggressiveness Scale (VAS). Previous research has documented the validity and reliability of the VAS as a measure of trait verbal aggressiveness (see Infante, 1987; Infante \& Rancer, 1996; Wigley, 1998). In the present study, the mean for this scale was 50.20 , the standard deviation was 10.99 , and the alpha reliability coefficient was .82 .

\section{RESULTS}

\section{Psychoticism and Trait Verbal Aggressiveness}

A significant Pearson product-moment correlation between psychoticism scores and VAS scores supported hypothesis $1(r=.50, p<.05)$. As predicted, psychoticism is positively associated with trait verbal aggressiveness. ${ }^{3}$

\section{Neuroticism-Psychoticism Interaction}

A multiple regression model employing neuroticism scores, psychoticism scores, and a multiplicative interaction term $(\mathrm{N} \times \mathrm{P})$ accounted for 27.04 percent of the variance in trait verbal aggressiveness scores $\left(R^{2}=.27, F=35.64, d f=3 / 290, p<.05\right)$. Neither neuroticism $(b=-.29, t=-1.65$, n.s.) nor psychoticism $(b=.10, t<1$, n.s.) contributed significantly to the prediction. As predicted, however, the multiplicative interaction term entered last was significant $(b=.58, t=2.29, p<.05)$.

In order to explore the nature of the interaction, (1) trait verbal aggressiveness scores were regressed on neuroticism scores separately for high and low psychoticism participants, and (2) the point of intersection for the two regression lines was calculated (Kerlinger \& Pedhuzar, 1973). The resulting regression lines for participants scoring at least one standard deviation above the mean $(n=61)$ on psychoticism (intercept $=50.11$, slope $=.27$ ) and those scoring at least one standard deviation below the mean $(n=64)$ on psychoticism (intercept $=44.25$, slope $=-.07$ ) intersected outside the range of interest for neuroticism (point of intersection $=-34.25$ ), indicating an ordinal interaction between neuroticism and psychoticism. The positive association of neuroticism with trait verbal aggressiveness for persons high in psychoticism is consistent with Beatty and McCroskey's (1997) theorizing.

\section{Extraversion-Psychoticism Interaction}

A multiple regression equation using extraversion, psychoticism, and a multiplicative interaction term (E X P) accounted for $\mathbf{2 8 . 0 9}$ percent of the variance in trait verbal aggressiveness scores $\left(R^{2}=.28, F=37.89, d f=3 / 290, p<.05\right)$ with extraversion $(b=.68, t=3.71, p<.05)$, psychoticism $(b=1.52, t=5.41, p<.05)$ and the interaction 
term $(b=-1.12, t=-3.67, p<.05)$ all contributing to the equation. Inspection of the separate regression lines for participants scoring at least one standard deviation above the mean on psychoticism (intercept $=79.67$, slope $=-.61$ ) and those scoring at least one standard deviation below the mean (intercept $=27.34$, slope $=.39$ ) revealed that the point of intersection (intersection $=52.33$ ) was slightly beyond the maximum score for extraversion (i.e., 50), indicating an ordinal interaction. However, as the regression parameters demonstrate, higher levels of extraversion were associated with lower levels of trait verbal aggressiveness for participants high in psychoticism. Higher extraversion scores were associated with higher trait verbal aggressiveness only for those low in psychoticism. While statistically significant, this pattern of results contradicts assumptions regarding an instrumental or proactive function.

\section{Full Equation}

A regression equation using the variables that were significant predictors in the preceding analyses, accounted for 30.25 percent of the variance in trait verbal aggressiveness scores $\left(R^{2}=.30, F=31.65, d f=4 / 289, p<.05\right)$ with extraversion $(b=.76$, $t=4.16)$, psychoticism $(b=1.47, t=5.31)$, the extraversion $x$ psychoticism interaction term $(b=-1.24, t=-4.11)$ and the neuroticism $x$ psychoticism interaction term $(b=.22$, $t=3.10)$ all contributing significantly to the equation $(p<.05)$.

\section{DISCUSSION}

The results of the present study have important theoretical implications for the study of verbal aggressiveness. In light of previous research indicating that psychoticism represents a psychological manifestation of FFS reactivity, the positive correlation between psychoticism and VAS scores provides empirical support for Beatty and McCroskey's (1997) theorizing about the relationship between psychoticism and trait verbal aggressiveness. Importantly, the magnitude of the correlation coefficient $(r=.50)$ meets the criterion for a "large" effect under Cohen's (1988) rubric, and further underscores the potential predictive power of the model when corrected for attenuation $(r=.63)$. In addition, the results of regression analysis revealed evidence that the effects of psychoticism were moderated by neuroticism, which has been strongly linked to BIS sensitivity. Examination of the ordinal interaction between neuroticism and psychoticism confirmed a positive association between neuroticism and VAS scores for respondents who were high in psychoticism. This finding is consistent with Beatty and McCroskey's (1997) contention that trait verbal aggressiveness requires a balance between BIS and FFS activity.

The findings for extraversion run counter to expectations regarding a proactive or instrumental function of trait verbal aggressiveness. Inspection of the interaction showed a negative association between extraversion and trait verbal aggressiveness for respondents who were high in psychoticism. Respondents who were low in psychoticism tended to be less passive toward the extraversion end of the continuum. Because previous research connects BAS reactivity with extraversion, the pattern of results for extraversion contradicts the hypothesis that trait verbal aggressiveness involves proactivity. Indeed, the results of the present study suggest that persons high in trait verbal aggressiveness are more likely psychotic introverts than psychotic extraverts.

Although persons who are not generally aggressive may employ forceful messages to gain rhetorical advantages, the findings for extraversion, in conjunction with the 
results for neuroticism, point toward a purely reactive trait. This conclusion, however, is inextricably linked to the content of the VAS. In order to minimize social desirability response bias, Infante and Wigley (1986) crafted the items to allow respondents to justify aggressive behavior, by qualifying the targets' behavior as "unreasonable" or "stupid." As a consequence, the VAS does not contain items that uniquely tap potential proactive forms of verbal aggressiveness (e.g., initiate an encounter with strategically planned aggressiveness for the purpose of intimidating another). Future research should examine the relationship between items measuring proactive forms of aggressiveness and the VAS. At the same time, these results for extraversion are consistent with Infante's proposition that verbal aggressiveness involves deficiencies in argumentation skills (see Infante, 1987). Certainly, Eysenck and Eysenck (1985) noted that introverts lack social experience and a number of social skills, including assertiveness. Verbal aggressiveness, therefore, may be the only viable means of expressing hostility arising from FFS reactions for those low in argumentation skills. The neurobiological foundation of extraversion-introversion, however, greatly complicates remedial proposals based on skills training. For instance, in a recent study, Rancer, Whitecap, Kosberg, and Avtgis (1997) were unable to reduce levels of trait verbal aggressiveness even after training in argumentativeness.

The potential predictive power of Beatty and McCroskey's (1997) model was further underscored by the regression model employing extraversion, psychoticism, the extraversion $x$ psychoticism and the neuroticism $\times$ psychoticism interaction terms which accounted for approximately 30 percent of the variance in VAS scores. Like the correlation between psychoticism and VAS scores, the magnitude of the effect is considered "large" (Cohen, 1988). Furthermore, a multiple regression equation based on disattenuated correlation coefficients among those variables accounted for approximately 46 percent of the variance in VAS scores $\left(R^{2}=.46\right)$.

Although the variance explained by the model tested in the present study was substantial compared to effects usually reported in the social sciences (Cohen, 1988), the source of a little over one half of the variance in trait verbal aggressiveness remains undocumented. Eysenck and Eysenck (1985) point out that effect sizes must always be interpreted within the psychometric limitations of the measures employed. Although reporting both attenuated and disattenuated correlations has become more common in recent years, Eysenck and Eysenck (1985) remind us that correlations are also bound by the validity of the measures. While the personality measures used in the present study were strongly linked to the neurobiological functioning posited by Gray (1991), they are not perfect estimates of psychoticism, neuroticism, and extraversion, and, they are obviously not perfectly isomorphic with FFS, BIS, and BAS reactivity.

Strictly speaking, we did not employ Eysenck's measures as direct measures of neurobiological functioning. Rather, we hypothesized relationships between verbal aggressiveness and personality dimensions based on the psychobiological literature which indicated common activation thresholds for the neurobiological systems underlying trait verbal aggressiveness and extraversion, neuroticism, and psychoticism. Clearly, further investigation of these personality measures as indices of BAS, BIS, and FFS sensitivity is warranted, especially within the context of social interaction. Because the hypothalamus is central to aggressive action, studies focussing on the relationships between the measures employed in this study and hypothalamus functioning are particularly relevant to trait verbal aggressiveness. Certainly, evidence of differential hypothalamus functioning attributable to trait 
verbal aggressiveness level during interaction would provide substantial support for Beatty and McCroskey's model.

A similar consideration applies to the validity of the VAS. For example, the largest validity estimate of the VAS obtained by Infante and Wigley (1986) was .69. Compared to most validity coefficients obtained in the behavioral sciences, the validity of the VAS would be considered excellent (Cronbach, 1970). As with all research findings, much of the variance unexplained in the present study is due to measurement error. While we were able to estimate effect sizes by removing error due to imperfect reliabilities, we did not provide quantitative estimates of the potential impact of imperfect validity. It may be that psychometric refinement of the measures used in the present study would produce effect sizes meeting more traditional criteria for high correlations (e.g., $r>$.70, Guilford, 1956).

The effect sizes reported in the present study underscore the potential predictive power of temperament-based or psychobiological models, which minimize the role of situational or environmental variables. Indeed scholars have increasingly moved toward genetic-based theories and away from environmentally based accounts of human behavior as the results of studies involving monozygotic and dizygotic twins, biochemical signatures of inherited neurobiological structures, and drug protocols accumulate. Over ten years ago, Eysenck (1986) commented that "the evidence from different investigators in the genetics of personality is quite clear-cut; genetic factors are more important than environmental factors" (p. 16). In addition to being weaker than genetic causes, the impact of environment is quite small. For example, scholars have noted trivial differences in correlations between twins' scores on trait measures, including aggressiveness, for twins reared together and those raised apart (e.g., Bouchard, 1993; Lykken, 1995; Zuckerman, 1994). In fact, the correlations are so similar that estimates of heritability can be accurately calculated on the basis of correlations from monozygotic and dizygotic twins who are raised together (Lykken, 1995).

Recent research shows that many of the effects previously attributed to environmental factors have genetic origins. Beatty and McCroskey (1997) note that the magnitude of associations between parents' behavior, for example, and children's personality and behavior have been on the small side. Furthermore, these authors suggest that the observed effects may be even smaller when genetic influences are removed. In their review of the parenting literature, Lish et al. (1996) reach a similar conclusion, pointing out that the small association found for parenting and children's aggression "may be merely an artifact of the genetic relationship between parenting and offspring" (p. 37). In addition to the evidence from twin studies, research correlating young adults' verbal aggressiveness scores with those of their parents lends support to the small effect of environment. Martin and Andersen (1997) reported correlations ranging from .03 to .32 between VAS (10-item version) scores for young adults and their parents. Consistent with the general aggressiveness research, the magnitude of the correlations is not indicative of powerful environmental effects.

In addition, genetic sources of personality variables contribute to the psychologically relevant dimensions of situations. For instance, studies show that persons respond to their subjective interpretations of events and that these interpretations are significantly moderated by genetic sources of personality, especially associated with extraversion and neuroticism (e.g., Phillips \& Matheny, 1997; Saudino, Pedersen, Lichtenstein, McClearn, \& Plomin, 1997; Saudino \& Plomin, 
1997). According to this line of research, personality contributes to life experience in at least four ways: (1) individuals seek experiences that are compatible with their personalities, (2) experiences are engendered by others' attributions about individuals, (3) interpretations of situations are driven by personality orientations, and (4) personality-driven responses contribute to the dynamics of the situations (Phillips \& Matheny, 1997). A wealth of research supports the idea that the neurobiologies of selective attention, perception, and recall processes function in a manner compatible with the neurobiology of personality (e.g., Derryberry \& Rothbart, 1988; Nelson, 1994; Posner, 1990). Accordingly, determinants of aggressive behavior which appear to represent situational factors are largely moderated by genetic sources. Although environmental effects cannot be completely ruled out, these findings (especially when viewed within the context of the psychobiological research literature) argue for a conceptualization in which genetically inherited neurobiological structures are the centerpieces of the construct.

\section{NOTES}

${ }^{1}$ Although numerous scholars have included biological factors in their conceptualizations of social interaction (A representative if not comprehensive review of this work can be gleaned from the following works: Beatty \& Dobos, 1997; Cappella, 1991; Horvath, 1998), Beatty and McCroskey's (1998) proposal differs considerably in breadth and substance. Beatty and McCroskey's framework is more closely related to "psychobiology" than "sociobiology." First, Beatty and McCroskey interpret the temperament work of the past decade as supporting a trait-oriented model of social interaction. Furthermore, they cite literature to support the view that at least $80 \%$ of communication processes are genetically inherited, referring to situational and environmental variables as "trivial" influences. Unlike most other communication scholars interested in biological influences (c.f., Horvath, 1998), Beatty and McCroskey rely heavily on studies of identical and fraternal twins. While a great deal of excellent scholarship by researchers interested in the biological features of human interaction processes has indeed accumulated, the literature reviewed in the present study was limited to the volumous recent work that is directly relevant to Beatty and McCroskey's theory of trait verbal aggressiveness.

${ }^{2}$ Readers concerned about contributions to the explained variance in VAS scores due to possible common method variance should note the small correlations among predictors reported in the method section. Common method effects should be observable across an entire correlation matrix calculated on data collected via common methods (e.g., self-report), not merely for theoretically expected relationships. Although common method variance should be examined as a routine procedure, not all data collected through common methods are confounded. In the present study, the low correlations among extraversion, neuroticism, and psychoticism suggest that while all three are self-report measures, participants differentiated among the items measuring each construct. Certainly, one of the attractive features of Eysenck's measures is their consistent orthogonal structure. Readers should note that Eysenck refined these measures over a four decade period. While many measures utilized in communication research are comparatively underdeveloped, Eysenck's measures provided a well-established set of instruments.

${ }^{3}$ The bivariate correlations for VAS and the other two predictors were VAS $\times E=-.05$ and VAS $x$ $N=.13$. Comparisons of the means and standard deviations obtained in the present study for $E$, $\mathrm{N}$, and $\mathrm{P}$ to those obtained by Eysenck are complicated by differences in response formats. Eysenck employed a two-foil "Yes-No" format whereas we sought to increase scale variability using a Likert-type format. However, estimates of the means and standard deviations based on 
a large sample $(N=1,254)$ not participating in the present study are similar to those reported in the present study (i.e., $\mathrm{E}, M=37.66$, $s d=5.37 ; \mathrm{N}, M=26.42, s d=7.38 ; \mathrm{P}, M=29.29$, $s d=8.33$ ).

\section{REFERENCES}

Adams, R. D., \& Victor, M. (1993). Principles of neurology (5th ed.). New York: McGraw-Hill.

Arnett, P. A., Howland, E. W., Smith, S. S., \& Newman, J. P. (1993). Automatic responsivity during passive avoidance in incarcerated psychopaths. Personality and Individual Differences, 14, 173-184.

Bates, J. E. (1987). Temperament in infancy. In J. D. Osofsky (Ed.), Handbook of infant development (2nd ed., pp. 1101-1149). New York: Wiley.

Bates, J. E. (1989). Concepts and measures of temperament. In G. A. Kohnstamm, J. E. Bates, \& M. K. Rothbart (Eds.), Temperament in childhood (pp. 3-26). New York: Wiley.

Beatty, M. J., \& Dobos, J. A. (1997). Physiological assessment. In J. A. Daly, J. C. McCroskey, J. Ayres, T. Hopf, \& D. M. Ayres (Eds.). Avoiding communication: Shyness, reticence, and communication apprehension (pp. 217-230). Cresskill, NJ: Hampton Press.

Beatty, M. J., \& McCroskey, J. C. (1997). It's in our nature: Verbal aggressiveness as temperamental expression. Communication Quarterly, 45, 446-460.

Beatty, M. J., \& McCroskey, J. C. (1998). Interpersonal communication as temperamental expression: A communibiological paradigm. In J. C. McCroskey, J. A. Daly, M. M. Martin, \& M. J. Beatty (Eds.), Communication and personality: Trait perspectioes. (pp.41-68). Cresskill, NJ: Hampton.

Beatty, M. J., McCroskey, J. C., \& Heisel, A. D. (1998). Communication apprehension as temperamental expression: A communibiological paradigm. Communication Monographs, 65, 197-219.

Bernhardt, P. C. (1997). Influences of seratonin and testosterone in aggression and dominance: Convergence with social psychology. Current Directions in Psychological Science, 6, 44-48.

Bouchard, T. J. (1993). Genetic and environmental influence on adult personality: Evaluating the evidence. In J. Hettema \& I. J. Deary (Eds.), Foundations of personality (pp. 15-44). Norwell, MA: Kluwer Academic.

Calkins, S. D., \& Fox, N. A. (1992). The relation among infant temperament, attachment, and behavioral inhibition at 24 months. Child Development, 63, 1456-1472.

Cappella, J. N. (1991). The biological origins of automated patterns of human interaction. Communication Theory, 1, 4-35.

Cates, D. S., Houston, B. K., Vavak, C. R., Crawfor, M. H., \& Uttley, M. (1993). Heritability of hostility-related emotions, attitudes and behaviors. Journal of Behavioral Medicine, 16, 237256.

Coccaro, E. F., Bergeman, C. S., \& McLearn, G. E. (1993). Heritability of irritable impulsiveness: A study of twins reared together and twins reared apart. Psychiatry Research, 48, 229-242.

Cohen, J. (1988). Statistical power analysis for the behavioral sciences (2nd ed.). Hillsdale, NJ: Lawrence Erlbaum.

Cowdry, R. W., \& Gardner, D. L. (1988). Pharmacotherapy of borderline personality disorder: Alprazolam, carbamazepine, trifluoperazine, and tranylcypromine. Archives of General Psychiatry, 45, 111-119.

Cronbach, L. J. (1970). Essentials of psychological testing (3rd ed.). New York: Harper \& Row.

Derryberry, D., \& Rothbart, M. K. (1988). Arousal, affect, and attention as components of temperament. Journal of Personality and Social Psychology, 55, 958-966.

DeTurck, M. A. (1987). When communication fails: Physical aggression as a compliance-gaining strategy. Communication Monographs, 54, 106-112. 
Dodge, K. A., \& Coie, J. D. (1987). Social-information-processing factors in reactive and proactive aggression in children's peer groups. Journal of Personality and Social Psychology, 53, 11461158.

Edelbrock, C., Render, R. D., Plomin, R., \& Thompson, L. A. (1995). A twin study of competence and problem behavior in childhood and early adolescence. Journal of Child Psychology and Psychiatry and Allied Disciplines, 36, 775-785.

Eley, T. C. (1997). General genes: A new theme in developmental psychopathology. Current Trends in Psychological Science, 6, 90-95.

Eysenck, H. J. (1986). Can personality study ever be scientific? Journal of Social Behavior and Personality, 1, 3-19.

Eysenck, H. J. (1991). Biological dimensions of personality. In L. A. Pervin (Ed.), Handbook of personality (pp. 244-276). New York: Guilford Press.

Eysenck, H. J., \& Eysenck, M. W. (1985). Personality and individual differences: A natural science approach. New York: Plenum.

Eysenck, S. B. G., Eysenck, H. J., \& Barrett, P. (1985). A revised version of the psychoticism scale. Personality and Individual Differences, 6, 21-29.

Fowles, D. C. (1980). The three arousal model: Implications of Gray's two-factor learning theory for heart rate, electrodermal activity, and psychopathy. Psychophysiology, 17, 87-104.

Geen, R. G. (1990). Human aggression. Pacific Grove, CA: Brooks/Cole.

Gray, J. A. (1991). The neuropsychology of temperament. In J. Strelau \& A. Angleitner (Eds.), Explorations in temperament (pp. 105-128). New York: Plenum.

Guilford, J. P. (1956). Fundamental statistics in psychology and education. New York: McGraw-Hill.

Horvath, C. W. (1995). Biological origins of communicator style. Communication Quarterly, 43, 394-407.

Horvath, C. W. (1998). Biological origins of communicator style. In J. C. McCroskey, J. A. Daly, M. M. Martin, \& M. J. Beatty, Communication and personality: Trait perspectives (pp. 69-94). Cresskill, NJ: Hampton Press.

Infante, D. A. (1987). Aggressiveness. In J. C. McCroskey \& J. A. Daly (Eds.), Personality and interpersonal communication (pp. 157-194). Newbury Park, CA: Sage.

Infante, D. A., Rancer, A. S. (1996). Argumentativeness and verbal aggressiveness: A review of recent theory and research. In B. R. Burleson \& A. W. Kunkel (Eds.), Communication yearbook, 19 (pp. 319-352). Thousand Oaks, CA: Sage.

Infante, D. A., \& Wigley, C. J., III (1986). Verbal aggressiveness: An interpersonal model and measure. Communication Monographs, 53, 61-69.

Kaplan, H. I., Sudock, B. J., \& Greb, J. A. (1994). Synopsis of psychiatry (7th ed.). Baltimore, MD: Williams and Wilkens.

Kavoussi, R., Liu, J., \& Coccaro, E. F. (1994). An open trial of sertraline in personality disorders patients with impulsive aggression. Journal of Clinical Psychiatry, 55, 137-141.

Lish, J. D., Kavoussi, R. J., \& Coccaro, E. F. (1996). Aggressiveness. In C. G. Costello (Ed.), Personality characteristics of the personality disordered (pp. 24-28). New York: John Wiley and Sons.

Lubin, A. (1961). The interpretation of significant interaction. Educational and Psychological Measurement, $21,807-817$.

Lykken, D. T. (1957). A study of anxiety in the sociopathic personality. Journal of Abnormal and Social Psychology, 55, 6-10.

Lykken, D. T. (1995). The antisocial personalities. Hillsdale, NJ: Lawrence Erlbaum.

Marieb, E. N., \& Mallatt, J. (1992). Human anatomy. Redwood City, CA: Benjamin/Cummings. 
Martin, M. M., \& Andersen, C. M. (1997). Aggressive communication traits: How similar are young adults and their parents in argumentativeness, assertiveness, and verbal aggressiveness? Western Journal of Communication, 61, 299-314.

Mattes, J. A. (1990). Comparative effectiveness of carbamazepine and propranolol for rage outbursts. Journal of Neuropsychiatry and Clinical Neurosciences, 2, 159-164.

Nelson, C. A. (1994). Neural basis of infant temperament. In J. E. Bates \& T. D. Wachs (Eds.), Temperament: Individual differences at the interface of biology and behavior (pp. 47-82). Washington, DC: American Psychological Association.

Panksepp, J. (1982). Toward a general psychobiology of emotions. Behavioral and Brain Research, $5,407-467$.

Panksepp, J. (1986). The anatomy of emotions. In R. Plutchik \& H. Kellerman (Eds.), Emotion: Theory research and experience: Biological foundations of emotions (Vol. 3, pp. 91-124). San Diego, CA: Academic Press.

Parens, H. (1989). Toward an epigenesus of aggression in early childhood. In S. I. Greenspan \& G. H. Pollock (Eds.). The course of life: Early childhood (Vol. 2, pp. 129-162). Madison, CT: International Universities Press.

Phillips, K., \& Matheny, A. P. (1997). Evidence for genetic influence on both cross-situation and situation-specific components of behavior. Journal of Personality and Social Psychology, 73, 129138.

Posner, M. I. (1990). Hierarchical distributed networks in the neuropsychology of selective attention. In A. Carramaza (Ed.), Cognitive neuropsychology and neurolinguistics: Advances in models of cognitive function and impairment (pp. 187-210). New York: Plenum.

Rancer, A. S., Whitecap, V. G., Kosberg, R. L., \& Avtgis, T. A. (1997). Training in argumentativeness: Testing the efficacy of a communication training program to increase argumentativeness and argumentative behavior in adolescents. Communication Education, 46, 273-286.

Roloff, M. E. (1996). The catalyst hypothesis: Conditions under which coercive communication leads to physical aggression. In D. D. Cahn \& S. A. Lloyd (Eds.), Family violence from a communication perspective (pp. 20-36). Thousand Oaks, CA: Sage.

Rothbart, M. K., Derryberry, D., \& Posner, M. I. (1994). A psychobiological approach to the development of temperament. In J. E. Bates \& T. D. Wachs (Eds.), Temperament: Individual differences at the interface of biology and behavior (pp. 83-116). Washington, DC: American Psychological Association.

Rushton, J. P., Fulker, D. W., Neal, M. C., Nias, D. K. B., \& Eysenck, H. J. (1986). Altruism and aggression: The heritability of individual differences. Journal of Personality and Social Psychology, 50, 1192-1198.

Saudino, K. J., Pedersen, N. L., Lichtenstein, P., McClearn, G. E., \& Plomin, R. (1997). Can personality explain genetic influences on life events? Journal of Personality and Social Psychology, 72, 196-206.

Saudino, K. J., \& Plomin, R. (1997). Cognitive and temperamental mediators of genetic contributions to the home environment during infancy. Merrill-Palmer Quarterly, 43, 1-23.

Soloff, P. H., George, A., Nathan, R. S., Schultz, P. M., \& Peril, J. M. (1986). Paradoxical effects of amitriptyline in borderline patients. American Journal of Psychiatry, 143, 1603-1605.

Spoont, M. R. (1992). Modulatory role of serotonin in neural information processing: Implications for human psychopathology. Psychological Bulletin, 112, 330-350.

Spoont, M. R. (1996). Emotional instability. In C. G. Costello (Ed.). Personality characteristics of the personality disordered (pp. 48-90). New York: Wiley. 
Steinmetz, J. E. (1994). Brain substrates of emotion and temperament. In J. E. Bates \& T. D. Wachs (Eds.), Temperament: Individual differences at the interface of biology and behavior (pp. 1746). Washington, DC: American Psychological Association.

Stelmack, R. M. (1990). Biological bases of extraversion: Psychophysiological evidence. Journal of Personality, 58, 293-311.

Strelau, J. (1983). Temperament, personality, activity. San Diego, CA: Academic Press.

Strelau, J. (1994). The concepts of arousal and arousability as used in temperament studies. In J. E. Bates \& T. D. Wachs (Eds.), Temperament: Individual differences at the interface of biology and behavior (pp. 117-141). Washington, DC: American Psychological Association.

Thomas, A., \& Chess, S. (1977). Temperament and development. New York: Brunner/Mazel.

Weiger, W. A., \& Bear, D. M. (1988). An approach to the neurology of aggression. Journal of Psychiatric Research, 22, 85-98.

Wigley, C. J. III (1998). Verbal aggressiveness. In J. C. McCroskey, J. A. Daly, M. M. Martin, \& M. J. Beatty (Eds.), Personality and communication: Trait perspectives (pp. 191-214). Cresskill, NJ: Hampton Press.

Zajonc, R. B., \& McIntosh, D. N. (1992). Emotions research: Some promising questions and some questionable promises. Psychological Science, 3, 70-74.

Zuckerman, M. (1994). Impulsive unsocialized sensation seeking: Biological dimension of a basic personality. In J. E. Bates \& T. D. Wachs (Eds.), Temperament: Individual differences at the interface of biology and behavior (pp. 219-255). Washington, DC: American Psychological Association.

Zuckerman, M. (1995). Good and bad humors: Biochemical bases of personality and its disorders. Psychological Science, 6, 325-332. 
Copyright of Communication Quarterly is the property of Eastern Communication Association and its content may not be copied or emailed to multiple sites or posted to a listserv without the copyright holder's express written permission. However, users may print, download, or email articles for individual use. 